\title{
Aesthetic \& Economical Management of Diastema
}

Dixit PB', Dixit S1

${ }^{1}$ Assistant Professors, Dental Department, Kathmandu Medical College Teaching Hospital, Sinamangal, Kathmandu, Nepal

\section{Abstract}

Diastema is a space between the teeth. Presence of diastema may lead to self-consciousness and patient may experience low self-esteem. Before closing the diastema, the cause must be understood and the treatment should be well planned. Diastemas are commonly closed by preparing the tooth \& restoring it with composite resin. Restorative method with composite resin is the least invasive, economical and aesthetic treatment which can be done in a single visit in comparison to all the other available treatment options.

Key words: Aesthetic, Diastema, Economical management

\section{INTRODUCTION}

$\mathrm{D}$ astema is defined as a space between teeth in the jaw ${ }^{1}$.Spacing in the full primary dentition is normal and are called as primate space which is an indicator of space available for the eruption of permanent dentition. According to Keene, midline diastema is anterior midline spacing greater than $0.5 \mathrm{~mm}$ between the proximal surfaces of adjacent teeth ${ }^{2}$.

Culturally, there has always been a mystique about diastematic women. In Ghana, Namibia, and Nigeria diastema is regarded as being attractive and a sign of fertility, and some people have even had them created through cosmetic dentistry. In France, they are called "dents du bonheur" or "lucky teeth"3.

Helvey enumerated the various causes of diastema which are as follows ${ }^{4}$ :

1. Transient malocclusion: Diastema occurs due to incipient malocclusion, which is usually a selfcorrecting one. Parents worry about the anterior spacing of their child around the age of 9 or 10 , this is called 'Ugly duckling stage' which occurs due to eruption process of canine, and once the canine erupts spaces will close in most of the cases.

2. Discrepancy in the tooth size and arch length: Diastema occurs when the arch length exceeds the total mesiodistal width of all teeth,

Address for correspondence

Dr. Punam Basnet Dixit

Assistant Professor, Dental Department

Kathmandu Medical College Teaching Hospital, Sinamangal

Kathmandu, Nepal

Email: docpunam@hotmail.com when there is missing teeth and there is drifting of the adjacent teeth in the missing tooth space.

3. High frenum attachment: $A$ thick and fleshy labial frenum attached high on the labial alveolar bone will resist the approximation of the two incisors resulting in midline diastema.

4. Habits: Chronic pressure habits like thumb sucking and tongue thrusting will predispose to midline diastema, which results in generalized anterior spacing with proclination of maxillary anteriors.

5. Pathology: Any kind of soft tissue or bone pathology in the jaw like cysts, tumors, osteoclastoma and unerupted mesiodens may result in diastema

6. latrogenic: Rapid maxillary expansion is one of the most frequent orthodontic treatments which will result in diastema.

7. Racial and genetic: Some races like Negroids have bigger jaw bone resulting in diastema. Midline diastema is also seen associated with genetic inheritance.

\section{CASE REPORTS \\ CASE 1 (FIGURE 3 AND 4):}

A 29 year old male came to dental department, Kathmandu Medical College and Teaching Hospital, Sinamangal requesting for closing the gap in between his central incisors. Various treatment options were discussed with the patient, but due to lack of time, patient decided to go for composite build up. Scaling of two central incisors was done and the shade of his anterior teeth was selected with Ceram.X duo shade system (Dentsply). Mesial aspect of both central incisors were roughened with coarse cut tapered fissure bur, tooth 
isolated and etched with Conditioner 36 (Dentsply) for 10 seconds. After washing the etchant, tooth was dried and then Prime \& Bond (Dentsply) was applied with an applicator tip (Dentsply) and light cured. Composite build up from mesial aspect of the central incisors following the layered technique was done with Ceram.X composite (Dentsply) with the help of Mylar strip (Samit Products). With an articulating paper, bite was adjusted then finishing \& polishing of the restoration was done with smooth tapered diamond bur (Shofu preparation set) and Enhance polishing kit (Dentsply).

\section{CASE 2 (FIGURE 5 AND 6)}

A 20 year old male patient came to the dental department, Kathmandu Medical College and Teaching Hsopital, requesting to close the gap in between his central incisors. He was referred by his brother (case 1) who had undergone the same procedure few days back in our department. First oral prophylaxis was done and then shade of the incisors was selected. The diastema was closed following the same procedure as in case 1.

\section{DISCUSSION}

With aesthetically compromised smiles, patients may become self-conscious, experience low self-esteem, and/or cover their mouths with their hands while speaking ${ }^{4}$. Diastema with significant tissue loss can change airflow between the teeth, resulting in obvious phonetic problems, particularly with ' $s$ ' and 'th' sounds'. A local cause for diastema must be identified and managed, if possible before the diastema can be closed to get a stable result. The ideal treatment should seek to manage not only the diastema in question but also the cause behind it ${ }^{6}$. For example if the diastema is present due to tongue thrusting habit, and it is closed without stopping the habit; then within a few years' time, the patient will again develop diastema as tongue is continuously pushing the incisors labially. Therefore patient must be made aware of his/her habit and different treatment modalities must be done to stop the tongue thrusting habit before treating the diastema to get a stable result. Approaches may vary from use of reversible, noninvasive techniques such as composite bonding; to irreversible, invasive treatments such as ceramic veneers or crowns ${ }^{4}$.

Frazier-Bowers and Maxbauer listed various treatment options for diastema closure which are as follows ${ }^{7}$ :

1. Keep the diastema

2. Diastema closure with direct composite resin

3. Orthodontic treatment to move the teeth and close the diastema

4. Use porcelain veneers to close the diastema

5. Crown and bridge to close the diastema, which is usually done in adults

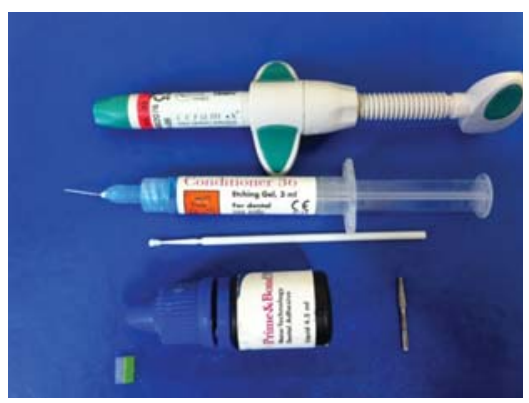

Figure 1: Composite Restorative Materials

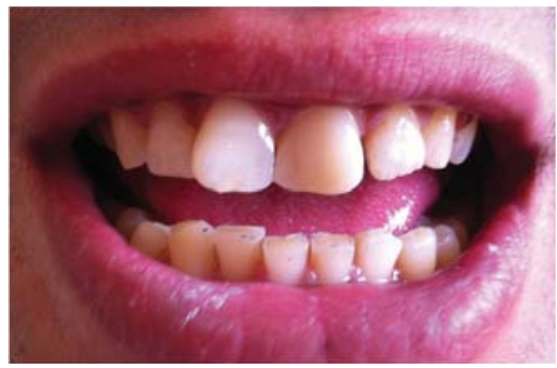

Figure 4 : Case 1 After Diastema Closure

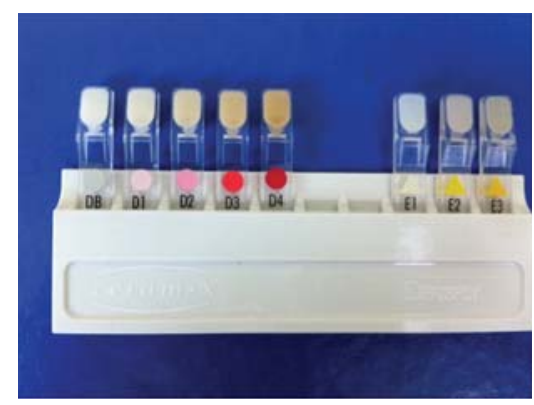

Figure 2: Shade Guide

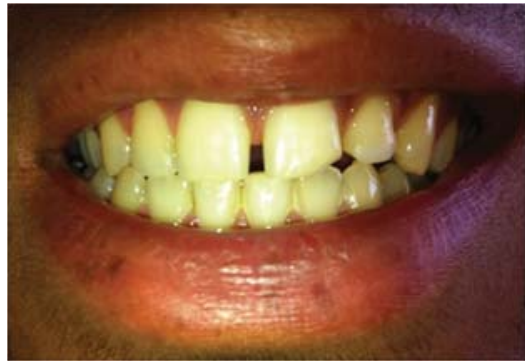

Figure 5: Case 2 Before Treatment

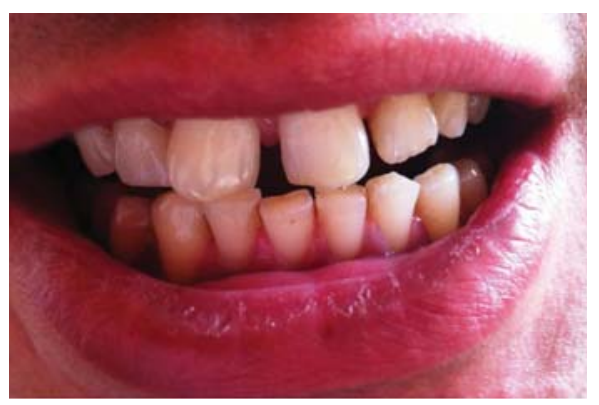

Figure 3: Case 1 Before Diastema Closure

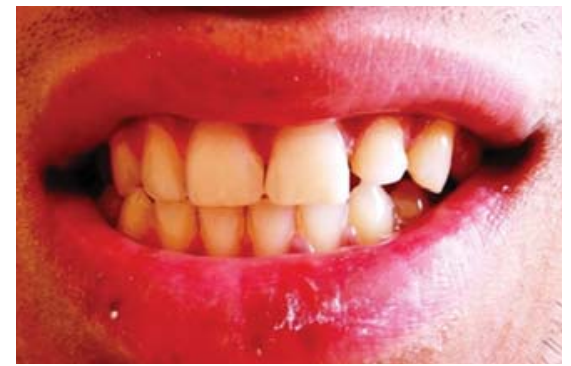

Figure 6: Case 2 After Treatment 
6. Make the patient aware of the habit and plan for habit breaking appliance

7. Remove the underlying pathology surgically, and then continue with closure of diastema with restorative material

While doing diastema closures with direct composites there are four keys to long term and aesthetic success ${ }^{8}$. First is good isolation of the entire surface to be bonded. Second is bonding to supragingival and subgingival enamel that will help to improve the bond strength of the restoration as well as improve the aesthetics. By beginning subgingivally, the emergence profile of the composite will look very natural. The third key to success is roughening the enamel on the surface of the tooth with course diamond so that the scratches on the tooth are visible with the naked eye. This roughness will increase the surface area to be bonded which in turn will improve the retention of restorative material to the tooth surface. And the fourth one is to bond and taper the composite to proximal one third of the tooth which will increase the surface area and will provide more aesthetically pleasing result.

Schwartz et al explained the Biomimetic Rules to create natural appearing diastema closure ${ }^{9}$. According to the author, anatomically, the cusp of an anterior tooth is governed by the rule of three; which states that each cusp is composed of three developmental lobes mesial, distal and central; and each lobe possesses character that defines itself and its control over its anatomic position. First the space in between the teeth is measured, then that measurement is divided into half. The quotient is added to the existing width of each tooth which gives the new tooth width. This new width is divided into thirds, mesial lobe will occupy one third, and central and distal lobe will occupy the remaining two thirds. Author also stated that the width of the maxillary incisors are two millimeters less that their length, the contact of the anterior teeth is in lingual half of buccolingual dimension and the most apical aspect of anterior contacts should be between three to five millimeters to the interdental crestal bone to avoid black triangles and impingement of the biologic width.

In cases which involve closure of complex diastema, determining the proper proportions dictates the amount of distal proximal reduction; whether to completely veneer the teeth or add to the interproximal zone; the number of teeth to be treated; and the position of prominences and concavities ${ }^{10}$. Special attention must be made if there are any occlusal concerns like bruxing or deep bite as direct restorations may not be successful ${ }^{9}$. To close the complex diastema indirect techniques are used, they generally require multiple visits to enable proper placement of the laminates, crowns, or bridgework, and such procedures may also involve significant financial expenses ${ }^{10}$.

In the presented case 1, though Orthopantomogram and orthodontic treatment was suggested to the patient, due to the patient's lack of time diastema was closed with composite restoration. This is a least invasive and reversible treatment because tooth surface is just roughened and not cut as in veneers or crowns. If the bond between the restoration and the tooth fails and the restoration fractures, there is no change in the original anatomy of the tooth, it remains as it was prior to the treatment. The tooth can be re-restored with the composite to close the diastema. After the restoration if patient is not happy with the outcome, the restoration can be removed without damaging the tooth structure. The cost of treatment is very less in comparison with other treatment options like orthodontic treatment, veneers and crown. The time taken to close the gap is also very less as it can be done in a single visit when compared to other treatment option like indirect veneer and crowns which cannot be done in single visit and requires minimum of two to three visits whereas orthodontic treatment will take around few months to years. The composite resins is available in different shades therefore if the shade selection is done properly, only the operator and the patient knows about the treatment that has been done to close the space.

\section{CONCLUSION}

A space between the teeth especially in the upper anterior jaw is very obvious and may compromise aesthetics and phonetics which may make people selfconscious. To avoid such problems the gap needs to be filled. Restorative method with composite resin is the least invasive, reversible, economic and aesthetic treatment which can be done in a single visit in comparison with all other available treatment options. 


\section{REFERENCES}

1. Collins English Dictionary - Complete and Unabridged [Internet]. 10th ed. [place unknown]: William Collins Sons \& Co. Ltd; 2009. Diastema; [cited 2012 Jul 30]. Available from: http://dictionary. reference.com/browse/diastema

2. Keene HJ. Distribution of diastemas in the dentition of man. Am J Phys Anthropol. 1963;21:437-41.

3. Midline diastemata in fashion [Internet]. [place unknown]: Bite Magazine. 2010 Oct 14 [cited 2010 Sep 10]. Available from: http://bitemagazine.com. au/news_blog/?p=190

4. Helvey GA. Closing diastemas and creating artificial gingiva with polymer ceramics. Compend Contin Educ Dent. 2002;23(11):983-96.

5. Tallents RH. Artificial gingival replacements. Oral Health. 1983;73(2):37-40

6. Alam MK. The multidisciplinary management of Median Diastema. Bangladesh J Med Sci. 2010;9(4):234-7.
7. Frazier-Bowers S, Maxbauer E. Orthodontics. In: Dental Hygiene Concepts, Cases, and Competencies. [place unknown]: Mosby; 2008. p. 699-706.

8. Diastema closure [Internet]. Owensville, $\mathrm{OH}$ : Greater Curve; 2010 [cited 2010 Nov 13]. Available from: www.greatercurve.com/DiastemaClosure.htm

9. Christopher CK. Diastema closure with a microhybrid composite resin [Internet]. [place unknown]. Available from: www.pdfplace.net/.../Diastemaclosure-with-a-micro-hybrid-composite resin

10. Blitz N. Direct bonding in diastema closure high drama, immediate resolution. Oral Health. 1996;86(7):23-6.

11. Lacy AM. Application of composite resin for single-appointment anterior and posterior diastema closure. Pract Periodontics Aesthet Dent. 1998;10(3):279-86.

12. Gillen RJ, Schwartz RS, Hilton TJ. An analysis of selected normative tooth proportions. Int J Prosthodont. 1994;7:410-7. 